\title{
Strong Associations between Plasma Osteopontin and Several Inflammatory Chemokines, Cytokines, and Growth Factors
}

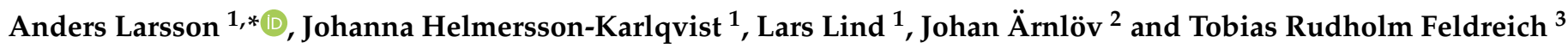 \\ 1 Department of Medical Sciences, Uppsala University, 75185 Uppsala, Sweden; \\ johanna.helmersson.karlqvist@akademiska.se (J.H.-K.); lars.lind@medsci.uu.se (L.L.) \\ 2 Division of Family Medicine and Primary Care, Department of Neurobiology, Care Sciences and \\ Society (NVS), Karolinska Institutet, 17177 Stockholm, Sweden; johan.arnlov@ki.se \\ 3 School of Health and Social Sciences, Dalarna University, 79188 Falun, Sweden; trf@du.se \\ * Correspondence: anders.larsson@akademiska.se; Tel.: +46-(18)-6114271
}

\section{check for} updates

Citation: Larsson, A. Helmersson-Karlqvist, J.; Lind, L.; Ärnlöv, J.; Feldreich, T.R. Strong Associations between Plasma Osteopontin and Several Inflammatory Chemokines, Cytokines, and Growth Factors. Biomedicines 2021, 9, 908. https:// doi.org/10.3390/biomedicines 9080908

Academic Editor:

Giuseppe Cappellano

Received: 8 June 2021

Accepted: 22 July 2021

Published: 28 July 2021

Publisher's Note: MDPI stays neutral with regard to jurisdictional claims in published maps and institutional affiliations.

Copyright: (c) 2021 by the authors. Licensee MDPI, Basel, Switzerland. This article is an open access article distributed under the terms and conditions of the Creative Commons Attribution (CC BY) license (https:// creativecommons.org/licenses/by/ $4.0 /)$.

\begin{abstract}
Osteopontin is a member of the proinflammatory cytokine network, a complex system that involves many chemokines, cytokines, and growth factors. The aim of the present study was to study the associations between osteopontin and a large number of chemokines, cytokines, and growth factors. We analyzed plasma and urine osteopontin in 652 men from the Uppsala Longitudinal Study of Adult Men (ULSAM) study cohort and compared the levels with the levels of eightyfive chemokines, cytokines, and growth factors. We found significant associations between plasma osteopontin and 37 plasma biomarkers in a model adjusted for age, and 28 of those plasma biomarkers were significant in a model also adjusting for cardiovascular risk factors. There were no significant associations after Bonferroni adjustment between urine osteopontin and any of the studied plasma cytokine biomarkers. This study shows that circulating osteopontin participates in a protein-protein interaction network of chemokines, cytokines, and growth factors. The network contains responses, pathways, and receptor binding interactions relating to cytokines, regulation of the immune system, and also regulation of apoptosis and intracellular signal transduction.
\end{abstract}

Keywords: osteopontin; plasma; urine; proinflammatory cytokines; chemokines

\section{Introduction}

Osteopontin (OPN) was first identified in 1985 [1]. The name, osteopontin, indicates that the protein is expressed in bone, but it is also secreted into plasma and urine and found in several other tissues. Therefore, osteopontin thus functions beyond those related to bone formation. Osteopontin has been implicated in several physiological and pathological processes such as bone turnover [2], cell survival [3], immune regulation and response [4], inflammation [5], ischemia [6], tissue remodeling [7], tumor progression [8], and wound healing [9]. In inflammation, osteopontin acts as a proinflammatory cytokine, modulating the immune response by enhancing expression of Th1 cytokines [10]. Proinflammatory cytokines function within a complex network, stimulating the release of one another, including both cytokine agonists and antagonists. There is limited information on the interactions between osteopontin and other inflammatory chemokines, cytokines, and growth factors. In the present study, we investigated the associations between proinflammatory cytokines reported to be associated with cardiovascular diseases and osteopontin in plasma and urine to increase our knowledge on the interactions between osteopontin and soluble chemokines, cytokines, and growth factors. We used an ELISA from R\&D Systems to quantify osteopontin in plasma and urine and correlated the osteopontin levels with the plasma levels of eighty-five chemokines, cytokines, and growth factors.

The aim of this study was to investigate the associations between plasma and urine osteopontin and a broad panel of plasma cytokines using the Proseek Multiplex Cardiovas- 
cular I panel. The multiplex proximity extension assays (PEA) simultaneously detected 92 chemokines, cytokines, and growth factors in the same sample.

\section{Materials and Methods}

\subsection{Patients}

The Uppsala Longitudinal Study of Adult Men (ULSAM) study cohort, described in detail at http:/ /www.pubcare.uu.se/ulsam (accessed on 1 June 2021), is an ongoing study since 1970 [11]; the inclusion criteria were 50-year-old male and a resident of Uppsala County, Sweden. The present study uses data from participants who were 77 years old. After exclusion of individuals lacking plasma or urine osteopontin values, 652 participants were included in the plasma part and 457 participants in the urine part of the study. The ULSAM study was approved by the Institutional review board and the Ethics Committee of Uppsala University (Dnr 251/90 (August 1990) and 97/329 (August 1997)).

\subsection{Clinical Characteristics}

Body mass index (BMI) was calculated using standardized methods and expressed in $\mathrm{kg} / \mathrm{m}^{2}$. Blood pressure was recorded, and data were extracted from a questionnaire completed by the participants regarding socioeconomic status, medical history, smoking habits, medication, and physical activity [8]. The blood pressures were measured at the time as the blood collection. Diabetes mellitus was diagnosed based on fasting plasma glucose $(\geq 7.0 \mathrm{mmol} / \mathrm{L})$ or use of antidiabetic medication.

\subsection{Osteopontin Measurements}

Plasma and urine osteopontin were measured using a commercial sandwich enzymelinked immunosorbent assay (ELISA) kit (DY1433, R\&D Systems, Minneapolis, MN, USA), as previously reported [12]. The limit of quantification (LOQ) of the Osteopontin ELISA was $62 \mathrm{pg} / \mathrm{mL}$. None of the test results were below LOQ. The total coefficient of variation for the ELISA was approximately $6 \%$. The laboratory testing was preformed blinded without knowledge of clinical data.

\subsection{Proseek Multiplex Measurements}

The plasma and urinary chemokines, cytokines, and growth factors were analyzed using Proseek Multiplex Cardiovascular I panel (Olink Bioscience, Uppsala, Sweden). Briefly, $1 \mu \mathrm{L}$ plasma was mixed with $3 \mu \mathrm{L}$ incubation mix containing paired antibodies labeled with unique corresponding DNA oligonucleotides. First, the mixture was incubated overnight at $8{ }^{\circ} \mathrm{C}$. Then, $96 \mu \mathrm{L}$ extension mix containing PEA enzyme and PCR reagents was added, and the samples were incubated for $5 \mathrm{~min}$ at room temperature before the plate was transferred to a thermal cycler for 17 cycles of DNA amplification. A 96.96 Dynamic Array IFC (Fluidigm, South San Francisco, CA, USA) was prepared and primed, according to the manufacturer's instructions. In a separate plate, $2.8 \mu \mathrm{L}$ of sample mixture was mixed with $7.2 \mu \mathrm{L}$ detection mix from which $5 \mu \mathrm{L}$ was loaded into the right side of the primed 96.96 Dynamic Array IFC. The unique primer pairs for each cytokine were loaded into the left side of the 96.96 Dynamic Array IFC, and the protein expression program was run in Fluidigm Biomark reader, according to the instructions for Proseek.

\subsection{Statistics}

Statistical software STATA 15 (StataCorp, College Station, TX, USA) was used in all analyses. Logarithmic transformation was used to promote a normal distribution of osteopontin.

We investigated the associations between plasma and urinary osteopontin, and plasma chemokines, cytokines, and growth factors using the following multivariable linear regression models:

A. Age-adjusted model; 
B. Cardiovascular risk factor model (model A + lipid-lowering treatment, cardiovascular diagnosis, body mass index, diabetes, antihypertensive treatments, systolic and diastolic blood pressure, total and high-density lipoprotein [HDL] cholesterol, and smoking).

In all analyses, urinary and plasma osteopontin were expressed per standard deviation increase. Multiple imputation methods were used to account for the potential influence of missing data with reference to the covariates. Cytokine values above or below the highest and lowest standard points in the Proseek panel were assigned the values of these points. Cytokines with less than $85 \%$ of the results in the quantitative range of the Proseek panel were excluded from the comparison. Protein levels in the Proseek panel were measured on a $\log 2$ scale and further transformed to a SD scale to be easily comparable. Linear regression analysis was applied to relate plasma and urine osteopontin to the levels of individual cytokines in the Cardiovascular I panel. Analyzing a large number of relationships increases the risk of false positive findings; therefore, the $p$-values were adjusted for multiplicity using the Bonferroni adjustment.

\subsection{Network Analysis}

The protein-protein interaction network for osteopontin and the cytokines significantly associated with osteopontin in the present study were investigated using the online database tool Search Tool for Retrieval of Interacting Genes/Proteins (STRING; https:/ / string-db.org/, accessed on 1 June 2021). The Uniprot numbers were entered in the search engine (multiple proteins) of STRING with the following parameters: organism Homo sapiens, maximum number of interactions was query proteins only, interaction score was set to minimum required interaction score of medium confidence (0.400). In the network figure, each cytokine/chemokine/growth factor is represented by a colored node, and protein-protein interaction and association are represented by an edge visualized as a line. Higher combined confidence scores are represented by thicker lines/edges.

\section{Results}

\subsection{Study Cohort}

The basic characteristics of the study cohort are presented in Table 1. Among the patients, 75 patients had diabetes, three patients with type 1 diabetes and the remaining patients with type 2 diabetes.

Table 1. Basic characteristics of the population $(n=652)$.

\begin{tabular}{|c|c|c|c|c|}
\hline Variables & Mean & SD & Min & Max \\
\hline Age, years & 77.6 & 0.77 & 75.5 & 80.7 \\
\hline Body mass index & 26.28 & 3.46 & 17.6 & 41.3 \\
\hline Plasma osteopontin, ng/mL & 54.6 & 24.7 & 10.9 & 227.4 \\
\hline Urine osteopontin, $\mathrm{ng} / \mathrm{mL}$ & 113.2 & 64.2 & 0.727 & 363.6 \\
\hline Syst blood pressure, $\mathrm{mm} \mathrm{Hg}$ & 150.7 & 20.4 & 102 & 230 \\
\hline Diastolic blood pressure, $\mathrm{mm} \mathrm{Hg}$ & 81.2 & 9.7 & 52 & 115 \\
\hline Total cholesterol, mmol/L & 5.40 & 0.99 & 2.8 & 10.2 \\
\hline \multirow[t]{2}{*}{ HDL cholesterol, mmol/L } & 1.31 & 0.33 & 0.37 & 2.73 \\
\hline & Percentage & & & \\
\hline Smoking, \% & $8.5 \%$ & & & \\
\hline Diabetes, \% & $11.5 \%$ & & & \\
\hline Cardiovascular disease, $\%$ & $27.9 \%$ & & & \\
\hline Lipid-lowering treatment, $\%$ & $17.4 \%$ & & & \\
\hline Beta-blocker treatment, \% & $25.8 \%$ & & & \\
\hline Diuretics treatment, $\%$ & $16.6 \%$ & & & \\
\hline Ca channel blocker treatment, \% & $16.3 \%$ & & & \\
\hline ACE-inhibitor treatment, $\%$ & $17.5 \%$ & & & \\
\hline
\end{tabular}




\subsection{Significant Associations between Plasma Osteopontin and Plasma Cytokines}

There were no osteopontin results that were below LOQ. The multivariate model A showed significant associations between plasma osteopontin and 37 plasma biomarkers in the Proseek panel (Table 2, Figure 1, and Supplementary Table S1). The ten Proseek biomarkers with the strongest correlations to plasma osteopontin were TNF-related apoptosis-inducing ligand receptor 2 (TRAIL-R2) (beta value 0.369), macrophage colonystimulating factor $1(0.368)$, agouti-related protein (0.363), fibroblast growth factor 23 (0.343), tumor necrosis factor receptor $2(0.340)$, tumor necrosis factor receptor $1(0.335)$, growth differentiation factor $15(0.308)$, interleukin $6(0.307)$, adrenomedullin $(0.278)$, and endothelial cell-specific molecule 1 (0.275).

Table 2. Relationship between plasma osteopontin and the 40 cytokines that were most strongly associated with osteopontin. The correlations are adjusted for age. Significant $p$-values after Bonferroni adjustment $\left(p=5.88 \times 10^{-4}\right)$ are highlighted in grey. All proteins were ln-transformed, and then transformed to a SD scale. $n=652$. Table sorted by $p$-value. ci $=$ confidence interval. The abbreviations are used in Figure 1.

\begin{tabular}{|c|c|c|c|c|c|c|c|}
\hline Biomarker & Uniprot & Abbreviation & Beta & Se & Ci Lower & Ci Higher & $p$-Value \\
\hline Osteopontin & Q3LGB0 & SPP1 & & & & & \\
\hline Macrophage colony-stimulating factor 1 & P09603 & CSF1 & 0.368 & 0.037 & 0.295 & 0.44 & $6.75 \times 10^{-22}$ \\
\hline $\begin{array}{l}\text { TNF-related apoptosis-inducing ligand } \\
\text { receptor } 2\end{array}$ & O14763 & TNFRSF10B & 0.369 & 0.038 & 0.296 & 0.443 & $2.50 \times 10^{-21}$ \\
\hline Agouti-related protein & O00253 & AGRP & 0.363 & 0.037 & 0.29 & 0.436 & $4.43 \times 10^{-21}$ \\
\hline Tumor necrosis factor receptor 2 & P20333 & TNFRSF1B & 0.34 & 0.037 & 0.267 & 0.413 & $6.18 \times 10^{-19}$ \\
\hline Tumor necrosis factor receptor 1 & P19438 & TNFRSF1A & 0.335 & 0.037 & 0.263 & 0.407 & $1.41 \times 10^{-18}$ \\
\hline Fibroblast growth factor 23 (FGF-23) & Q9GZV9 & FGF23 & 0.343 & 0.038 & 0.268 & 0.418 & $3.02 \times 10^{-18}$ \\
\hline Growth differentiation factor 15 & Q99988 & GDF15 & 0.308 & 0.038 & 0.234 & 0.381 & $1.65 \times 10^{-15}$ \\
\hline Interleukin 6 & P05231 & IL6 & 0.307 & 0.039 & 0.231 & 0.383 & $1.08 \times 10^{-14}$ \\
\hline Adrenomedullin & P35318 & $\mathrm{ADM}$ & 0.278 & 0.037 & 0.205 & 0.351 & $3.23 \times 10^{-13}$ \\
\hline Endothelial cell-specific molecule 1 & Q9NQ30 & ESM1 & 0.275 & 0.037 & 0.202 & 0.348 & $5.22 \times 10^{-13}$ \\
\hline Urokinase plasminogen activator surface rec & Q03405 & PLAUR & 0.277 & 0.038 & 0.203 & 0.351 & $6.82 \times 10^{-13}$ \\
\hline Cathepsin L1 & P07711 & CTSL & 0.274 & 0.037 & 0.201 & 0.348 & $7.54 \times 10^{-13}$ \\
\hline Placenta growth factor & P49763 & PGF & 0.267 & 0.038 & 0.193 & 0.341 & $4.58 \times 10^{-12}$ \\
\hline Proteinase-activated receptor 1 & P25116 & F2R & 0.266 & 0.038 & 0.191 & 0.341 & $9.75 \times 10^{-12}$ \\
\hline Hepatocyte growth factor & P14210 & HGF & 0.263 & 0.038 & 0.188 & 0.337 & $1.14 \times 10^{-11}$ \\
\hline CD 40 ligand & P29965 & CD40LG & 0.258 & 0.038 & 0.183 & 0.333 & $2.76 \times 10^{-11}$ \\
\hline Matrix metalloproteinase-12 & P39900 & MMP12 & 0.248 & 0.038 & 0.173 & 0.323 & $1.95 \times 10^{-10}$ \\
\hline Interleukin $27 a$ & Q14213 & EBI3 & 0.236 & 0.037 & 0.162 & 0.309 & $5.70 \times 10^{-10}$ \\
\hline Matrix metalloproteinase 7 & P09237 & MMP7 & 0.233 & 0.038 & 0.158 & 0.308 & $1.73 \times 10^{-9}$ \\
\hline Thrombomodulin & P07204 & THBD & 0.211 & 0.039 & 0.135 & 0.286 & $6.69 \times 10^{-8}$ \\
\hline Chitinase-3-like protein 1 & P36222 & CHI3L1 & 0.212 & 0.039 & 0.136 & 0.289 & $7.10 \times 10^{-8}$ \\
\hline Osteoprotegerin & O00300 & TNFRSF11B & 0.204 & 0.038 & 0.129 & 0.279 & $1.44 \times 10^{-7}$ \\
\hline Spondin-1 & Q9HCB6 & SPON1 & 0.206 & 0.039 & 0.13 & 0.282 & $1.61 \times 10^{-7}$ \\
\hline Interleukin 16 & Q14005 & IL16 & 0.199 & 0.038 & 0.123 & 0.274 & $3.29 \times 10^{-7}$ \\
\hline TIM-1/KIM-1 & Q96D42 & HAVCR1 & 0.196 & 0.038 & 0.121 & 0.271 & $3.53 \times 10^{-7}$ \\
\hline Protein S100-A12 & P80511 & S100A12 & 0.198 & 0.039 & 0.121 & 0.275 & $5.74 \times 10^{-7}$ \\
\hline Interleukin-1 receptor antagonist protein & P18510 & IL1RN & 0.19 & 0.039 & 0.113 & 0.266 & $1.38 \times 10^{-6}$ \\
\hline Vascular endothelial growth factor A & P15692 & VEGFA & 0.186 & 0.038 & 0.11 & 0.261 & $1.68 \times 10^{-6}$ \\
\hline NT-proBNP & P16860 & NPPB & 0.185 & 0.038 & 0.11 & 0.261 & $1.79 \times 10^{-6}$ \\
\hline $\begin{array}{l}\text { Tumor necrosis factor receptor superfamily } \\
\text { member } 6\end{array}$ & P25445 & FAS & 0.183 & 0.039 & 0.107 & 0.258 & $2.54 \times 10^{-6}$ \\
\hline Matrix metalloproteinase 3 & P08254 & MMP3 & 0.175 & 0.039 & 0.099 & 0.252 & $8.53 \times 10^{-6}$ \\
\hline Resistin & Q9HD89 & RETN & 0.175 & 0.039 & 0.098 & 0.252 & $9.18 \times 10^{-6}$ \\
\hline Fractalkine & P78423 & CX3CL1 & 0.169 & 0.039 & 0.093 & 0.245 & 0.0000158 \\
\hline C-X-C motif chemokine 16 & Q9H2A7 & CXCL16 & 0.168 & 0.039 & 0.092 & 0.244 & 0.0000179 \\
\hline Beta-nerve growth factor & P01138 & NGF & 0.169 & 0.04 & 0.091 & 0.248 & 0.0000269 \\
\hline Kallikrein-11 & Q9UBX7 & KLK11 & 0.159 & 0.038 & 0.083 & 0.234 & 0.0000412 \\
\hline C-C motif chemokine 3 & P10147 & CCL3 & 0.163 & 0.04 & 0.085 & 0.241 & 0.000051 \\
\hline Interleukin 8 & P10145 & IL8 & 0.156 & 0.039 & 0.08 & 0.232 & 0.0000616 \\
\hline Cancer antigen 125 & Q8WXI7 & MUC16 & 0.152 & 0.039 & 0.076 & 0.229 & 0.0001033 \\
\hline TNFSF14 & O43557 & TNFSF14 & 0.152 & 0.039 & 0.076 & 0.229 & 0.0001105 \\
\hline
\end{tabular}






Figure 1. Forest plot showing the associations between plasma osteopontin and 85 biomarkers from the Proseek panel adjusted for age. Data are regression coefficients expressed per SD increase and 95\% confidence interval. 
The multivariate model B (after adjustment for CVD risk factors) showed that 28 plasma biomarkers remained significantly associated with plasma osteopontin (Table 3 and Supplementary Table S2). The ten Proseek biomarkers with the strongest correlations to plasma osteopontin were macrophage colony-stimulating factor 1 (beta value 0.351 ), agouti-related protein (0.341), TNF-related apoptosis-inducing ligand receptor $2(0.339)$, tumor necrosis factor receptor 1 (0.311), tumor necrosis factor receptor $2(0.307)$, fibroblast growth factor 23 (0.315), growth differentiation factor $15(0.298)$, interleukin $6(0.277)$, endothelial cell-specific molecule 1 (0.262), and adrenomedullin (0.273).

Table 3. Relationship between plasma osteopontin and each of the 40 cytokines that were most strongly associated with osteopontin in model B. Significant $p$-values after Bonferroni adjustment $\left(p=5.88 \times 10^{-4}\right)$ are highlighted in grey. All proteins were ln-transformed, and then transformed to a SD scale. $n=652$. Table sorted by $p$-value. ci $=$ confidence interval.

\begin{tabular}{|c|c|c|c|c|c|c|c|}
\hline Biomarker & Uniprot & Abbreviation & Beta & Se & $\begin{array}{c}\text { Ci } \\
\text { Lower }\end{array}$ & $\begin{array}{c}\text { Ci } \\
\text { Higher }\end{array}$ & $p$-Value \\
\hline Osteopontin & Q3LGB0 & SPP1 & & & & & \\
\hline Macrophage colony-stimulating factor 1 & P09603 & CSF1 & 0.351 & 0.038 & 0.277 & 0.424 & $1.71 \times 10^{-19}$ \\
\hline Agouti-related protein & O00253 & AGRP & 0.341 & 0.039 & 0.264 & 0.417 & $2.26 \times 10^{-17}$ \\
\hline TNF-related apoptosis-inducing ligand rec. 2 & O14763 & TNFRSF10B & 0.339 & 0.04 & 0.26 & 0.418 & $2.23 \times 10^{-16}$ \\
\hline Tumor necrosis factor receptor 1 & P19438 & TNFRSF1A & 0.311 & 0.039 & 0.234 & 0.388 & $1.08 \times 10^{-14}$ \\
\hline Tumor necrosis factor receptor 2 & P20333 & TNFRSF1B & 0.307 & 0.039 & 0.231 & 0.383 & $1.13 \times 10^{-14}$ \\
\hline Fibroblast growth factor 23 (FGF-23) & Q9GZV9 & FGF23 & 0.315 & 0.04 & 0.236 & 0.394 & $1.75 \times 10^{-14}$ \\
\hline Growth differentiation factor 15 & Q99988 & GDF15 & 0.298 & 0.042 & 0.217 & 0.38 & $2.14 \times 10^{-12}$ \\
\hline Interleukin 6 & P05231 & IL6 & 0.277 & 0.039 & 0.2 & 0.353 & $3.47 \times 10^{-12}$ \\
\hline Endothelial cell-specific molecule 1 & Q9NQ30 & ESM1 & 0.262 & 0.038 & 0.187 & 0.337 & $1.67 \times 10^{-11}$ \\
\hline Adrenomedullin & P35318 & ADM & 0.273 & 0.04 & 0.194 & 0.352 & $3.36 \times 10^{-11}$ \\
\hline Cathepsin L1 & P07711 & CTSL & 0.242 & 0.038 & 0.167 & 0.316 & $3.77 \times 10^{-10}$ \\
\hline Urokinase plasminogen activator surface rec & Q03405 & PLAUR & 0.237 & 0.039 & 0.161 & 0.314 & $1.92 \times 10^{-9}$ \\
\hline CD 40 ligand & P29965 & CD40LG & 0.232 & 0.039 & 0.156 & 0.307 & $2.95 \times 10^{-9}$ \\
\hline Placenta growth factor & P49763 & PGF & 0.234 & 0.039 & 0.157 & 0.31 & $4.29 \times 10^{-9}$ \\
\hline Proteinase-activated receptor 1 & P25116 & F2R & 0.228 & 0.039 & 0.151 & 0.305 & $1.06 \times 10^{-8}$ \\
\hline Hepatocyte growth factor & P14210 & HGF & 0.226 & 0.04 & 0.148 & 0.305 & $2.54 \times 10^{-8}$ \\
\hline Interleukin $27 \mathrm{a}$ & Q14213 & EBI3 & 0.213 & 0.038 & 0.138 & 0.288 & $3.51 \times 10^{-8}$ \\
\hline Thrombomodulin & P07204 & THBD & 0.202 & 0.038 & 0.127 & 0.277 & $1.73 \times 10^{-7}$ \\
\hline Matrix metalloproteinase 7 & P09237 & MMP7 & 0.215 & 0.041 & 0.134 & 0.295 & $2.49 \times 10^{-7}$ \\
\hline Matrix metalloproteinase-12 & P39900 & MMP12 & 0.208 & 0.041 & 0.127 & 0.289 & $6.64 \times 10^{-7}$ \\
\hline TIM-1/KIM-1 & Q96D42 & HAVCR1 & 0.207 & 0.042 & 0.125 & 0.289 & $8.56 \times 10^{-7}$ \\
\hline Chitinase-3-like protein 1 & P36222 & CHI3L1 & 0.193 & 0.039 & 0.116 & 0.27 & $1.26 \times 10^{-6}$ \\
\hline Osteoprotegerin & O00300 & TNFRSF11B & 0.186 & 0.039 & 0.111 & 0.262 & $1.67 \times 10^{-6}$ \\
\hline Interleukin 16 & Q14005 & IL16 & 0.183 & 0.038 & 0.108 & 0.258 & $1.93 \times 10^{-6}$ \\
\hline Spondin-1 & Q9HCB6 & SPON1 & 0.173 & 0.04 & 0.096 & 0.251 & 0.0000148 \\
\hline $\begin{array}{l}\text { Tumor necrosis factor receptor superfamily } \\
\text { member } 6\end{array}$ & P25445 & FAS & 0.167 & 0.038 & 0.092 & 0.242 & 0.0000154 \\
\hline Protein S100-A12 & P80511 & S100A12 & 0.168 & 0.039 & 0.091 & 0.244 & 0.0000219 \\
\hline Vascular endothelial growth factor A & P15692 & VEGFA & 0.16 & 0.038 & 0.086 & 0.235 & 0.0000281 \\
\hline Interleukin-1 receptor antagonist protein & P18510 & IL1RN & 0.163 & 0.041 & 0.083 & 0.243 & 0.0000698 \\
\hline Fractalkine & P78423 & CX3CL1 & 0.153 & 0.039 & 0.077 & 0.229 & 0.0000878 \\
\hline Beta-nerve growth factor & P01138 & NGF & 0.159 & 0.04 & 0.08 & 0.238 & 0.0000915 \\
\hline C-X-C motif chemokine 16 & Q9H2A7 & CXCL16 & 0.147 & 0.039 & 0.07 & 0.223 & 0.0001929 \\
\hline NT-proBNP & P16860 & NPPB & 0.154 & 0.042 & 0.073 & 0.236 & 0.0002357 \\
\hline Matrix metalloproteinase 3 & P08254 & MMP3 & 0.145 & 0.04 & 0.066 & 0.224 & 0.0003467 \\
\hline Tissue factor & P13726 & $\mathrm{TF}$ & 0.14 & 0.04 & 0.062 & 0.217 & 0.0004439 \\
\hline Interleukin 8 & P10145 & IL8 & 0.135 & 0.039 & 0.059 & 0.211 & 0.0005121 \\
\hline TNFSF14 & O43557 & TNFSF14 & 0.135 & 0.039 & 0.059 & 0.21 & 0.0005263 \\
\hline Cancer antigen 125 & Q8WXI7 & MUC16 & 0.135 & 0.039 & 0.058 & 0.212 & 0.0006385 \\
\hline $\mathrm{C}-\mathrm{C}$ motif chemokine 20 & P78556 & CCL20 & 0.13 & 0.039 & 0.053 & 0.207 & 0.0009732 \\
\hline SIR2-like protein 2 & Q8IXJ6 & SIRT2 & 0.126 & 0.039 & 0.05 & 0.203 & 0.0012322 \\
\hline
\end{tabular}

\subsection{Significant Associations between Urine Osteopontin and Plasma Cytokines}

Only tissue-type plasminogen activator, interleukin-1 receptor antagonist protein, thrombomodulin, angiopoietin-1 receptor, kallikrein-6, cathepsin D, and macrophage colony-stimulating factor 1 were significantly associated with osteopontin at $p<0.05$ in model A (Supplementary Table S3). However, none of the biomarkers remained significantly associated after Bonferroni adjustment. Similarly, in Model B thrombomodulin, 
macrophage colony-stimulating factor 1, kallikrein-6, and TNF receptor 1 were significantly associated before Bonferroni adjustment but not after the adjustment (Supplementary Table S3).

\subsection{Network Analysis}

The network and enrichment analysis of osteopontin and the 37 proteins significantly associated with osteopontin in Model A based on STRING database identified a proteinprotein interaction network that was highly and significantly enriched (protein-protein interaction $(\mathrm{PPI})$ enrichment $p$-value $\left.<1.0 \times 10^{-16}\right)$. Hence, most of these proteins interact with other proteins in the network. Among the 132 terms of biological process (BP) of GO with FDR $<1 \times 10^{-4}$ were responses, pathways, and receptor bindings relating to cytokines, regulation of immune system, as well as regulation of apoptosis and intracellular signal transduction (Supplementary Table S4).

\section{Discussion}

In the present study, we found associations between plasma osteopontin and several inflammatory chemokines, cytokines, and growth factors. In contrast, there were no significant associations found with urine osteopontin after Bonferroni adjustments. We have previously shown that urinary osteopontin was associated with chronic kidney disease while plasma osteopontin was related to cardiovascular disease. Osteopontin has been shown to be highly expressed in the kidney tubule cells (http: / www.proteinatlas.org / ENSG00000118785-SPP1/tissue/kidney\#imid_7707072, accessed on 1 June 2021). Thus, it is likely that urinary osteopontin mainly reflects a local kidney injury. In contrast, plasma osteopontin is part of the systemic inflammatory response. The analysis indicates that plasma osteopontin is part of a complex protein-protein interaction network according to existing bioinformatic data. The different biological processes that are influenced by the studied network are presented in Supplementary Table S5. The Olink technology is based on the combination of antibodies and DNA amplification. Despite the small sample volumes, the methodology achieves similar or higher sensitivity than traditional ELISAs (Supplementary Table S6).

Osteopontin expression is increased in response to pathophysiological conditions of the heart. Human studies and transgenic mouse models have shown that increased osteopontin production, especially in myocytes, was associated with increased apoptosis and myocardial dysfunction [13]. Experimental studies have indicated that osteopontin played an important role in atherosclerosis development, vascular remodeling, and restenosis [2,14-16]. It has also been shown that atherosclerosis modifying therapies with statins or angiotensin II inhibiting drugs reduced circulating osteopontin levels [17,18]. Osteopontin is a key player in the human inflammatory cytokine network with effects on several biological processes. Currently, we have limited knowledge of how osteopontin interacts with other cytokines. To be able to develop disease-specific osteopontin therapies, it is important to know the details of these interactions because we want to modify the disease specific effects without interfering with other biological processes.

The present multiplex protein panel analyzed in plasma was selected to include proteins with known or suggested links to CVD. We have previously found several of these proteins to be inflammatory chemokines, cytokines, and growth factors, which are associated with atherosclerosis and incident CVD [19-21]. We have also found plasma osteopontin to be associated with incident CVD [12]. Given the tight coupling between osteopontin and several inflammatory chemokines, cytokines, and growth factors demonstrated both by traditional statistics as well as protein-protein interaction network analysis, it is hard to separate the role of osteopontin in CVD from the other proteins. Future studies using Mendelian randomization are needed to determine which of the associations presented in the present study are causal or not and if osteopontin is causally related to CVD. 
A limitation of this study is the fact that the determination of broad cytokine panels is a relatively new concept and therefore, there are no internationally accepted calibrators for most of the studied biomarkers and no well-established reference values. The lack of international calibrators means that each company must develop their own calibrations which makes it difficult to compare results obtained with assays from different manufacturers.

In conclusion, the results of this study show that circulating osteopontin participates in a protein-protein interaction network of chemokines, cytokines, and growth factors. The network contains responses, pathways, and receptor binding interactions relating to cytokines, regulation of the immune system, and also regulation of apoptosis and intracellular signal transduction.

Supplementary Materials: The following are available online at https://www.mdpi.com/article/ 10.3390/biomedicines9080908/s1, Table S1: Relationship between plasma osteopontin and the 85 cytokines analyzed in the CVD panel. The correlations are adjusted for age. Table S2: Relationship between plasma osteopontin and the 85 cytokines that were most strongly associated with osteopontin in model B. Table S3: Relationship between urine osteopontin and the 85 cytokines analyzed in the CVD panel. Table S4: Relationship between urinary osteopontin and the 85 cytokines that were most strongly associated with osteopontin in model B. Table S5: The cytokines and the different biological processes that are influenced by the studied networks. Table S6: Lower and upper limits of quantification for the biomarkers included in the Proseek Multiplex Cardiovascular I panel.

Author Contributions: A.L., L.L., J.Ä. and T.R.F. conceived the study; J.Ä. and T.R.F. performed the statistical analysis; all authors have been involved in the analysis of data from the study; A.L. and J.H.-K. were responsible for the osteopontin measurements; J.Ä., L.L. and T.R.F. organized the PEA assays in the study; A.L., J.H.-K., J.Ä. and T.R.F. prepared the initial manuscript. All authors critically reviewed the manuscript and approved the final draft. All authors have read and agreed to the published version of the manuscript.

Funding: This research was supported by Njurfonden, The Swedish Research Council, Swedish Heart-Lung Foundation, the Marianne and Marcus Wallenberg Foundation, Dalarna University, and Uppsala University.

Institutional Review Board Statement: The study was conducted according to the guidelines of the Declaration of Helsinki, and approved by the Ethics Committee of Uppsala University (Dnr 251/90 (August 1990) and 97/329 (August 1997)).

Informed Consent Statement: Written informed consent was obtained from all subjects participating in the study.

Data Availability Statement: The datasets used and/or analyzed during the current study are available from the corresponding author on request. This will in most cases also require an ethical permit.

Conflicts of Interest: The authors declare no conflict of interest. The funders had no role in the design of the study; in the collection, analyses, or interpretation of data; in the writing of the manuscript, or in the decision to publish the results.

\section{References}

1. Franzén, A.; Heinegård, D. Isolation and characterization of two sialoproteins present only in bone calcified matrix. Biochem. J. 1985, 232, 715-724. [CrossRef] [PubMed]

2. Kosmopoulos, M.; Paschou, S.A.; Grapsa, J.; Anagnostis, P.; Vryonidou, A.; Goulis, D.G.; Siasos, G. The Emerging Role of Bone Markers in Diagnosis and Risk Stratification of Patients With Coronary Artery Disease. Angiology 2019, 70, 690-700. [CrossRef] [PubMed]

3. Iida, T.; Wagatsuma, K.; Hirayama, D.; Nakase, H. Is Osteopontin a Friend or Foe of Cell Apoptosis in Inflammatory Gastrointestinal and Liver Diseases? Int. J. Mol. Sci. 2017, 19, 7. [CrossRef]

4. Rittling, S.R.; Singh, R. Osteopontin in Immune-mediated Diseases. J. Dent. Res. 2015, 94, 1638-1645. [CrossRef] [PubMed]

5. Castello, L.M.; Raineri, D.; Salmi, L.; Clemente, N.; Vaschetto, R.; Quaglia, M.; Garzaro, M.; Gentilli, S.; Navalesi, P.; Cantaluppi, V.; et al. Osteopontin at the Crossroads of Inflammation and Tumor Progression. Mediat. Inflamm. 2017, 2017, 4049098. [CrossRef]

6. Zhu, Q.; Luo, X.; Zhang, J.; Liu, Y.; Luo, H.; Huang, Q.; Cheng, Y.; Xie, Z. Osteopontin as a Potential Therapeutic Target for Ischemic Stroke. Curr. Drug Deliv. 2017, 14, 766-772. [CrossRef] 
7. Bevan, L.; Lim, Z.W.; Venkatesh, B.; Riley, P.R.; Martin, P.; Richardson, R.J. Specific macrophage populations promote both cardiac scar deposition and subsequent resolution in adult zebrafish. Cardiovasc. Res. 2020, 116, 1357-1371. [CrossRef] [PubMed]

8. Zhao, H.; Chen, Q.; Alam, A.; Cui, J.; Suen, K.C.; Soo, A.P.; Eguchi, S.; Gu, J.; Ma, D. The role of osteopontin in the progression of solid organ tumour. Cell Death Dis. 2018, 9, 356. [CrossRef]

9. Chimento, S.; Billero, V.; Cavallin, L.; Romanelli, M.; Nadji, M.; Romanelli, P. Evaluation of osteopontin expression in chronic wounds: A potential prognostic and therapeutic biomarker. J. Wound Care 2017, 26, S4-S8. [CrossRef]

10. Bruemmer, D.; Collins, A.R.; Noh, G.; Wang, W.; Territo, M.; Arias-Magallona, S.; Fishbein, M.C.; Blaschke, F.; Kintscher, U.; Graf, K.; et al. Angiotensin II-accelerated atherosclerosis and aneurysm formation is attenuated in osteopontin-deficient mice. J. Clin. Investig. 2003, 112, 1318-1331. [CrossRef]

11. Byberg, L.; Siegbahn, A.; Berglund, L.; McKeigue, P.; Reneland, R.; Lithell, H. Plasminogen activator inhibitor-1 activity is independently related to both insulin sensitivity and serum triglycerides in 70-year-old men. Arterioscler. Thromb. Vasc. Biol. 1998, 18, 258-264. [CrossRef]

12. Feldreich, T.; Carlsson, A.C.; Helmersson-Karlqvist, J.; Risérus, U.; Larsson, A.; Lind, L.; Ärnlöv, J. Urinary Osteopontin Predicts Incident Chronic Kidney Disease, while Plasma Osteopontin Predicts Cardiovascular Death in Elderly Men. Cardioren. Med. 2017, 7, 245-254. [CrossRef]

13. Singh, M.; Dalal, S.; Singh, K. Osteopontin: At the cross-roads of myocyte survival and myocardial function. Life Sci. 2014, 118, 1-6. [CrossRef]

14. Sulkava, M.; Raitoharju, E.; Levula, M.; Seppälä, I.; Lyytikäinen, L.P.; Mennander, A.; Järvinen, O.; Zeitlin, R.; Salenius, J.P.; Illig, T.; et al. Differentially expressed genes and canonical pathway expression in human atherosclerotic plaques-Tampere Vascular Study. Sci. Rep. 2017, 7, 41483. [CrossRef]

15. Yilmaz, K.C.; Bal, U.A.; Karacaglar, E.; Okyay, K.; Aydinalp, A.; Yildirir, A.; Muderrisoglu, H. Plasma osteopontin concentration is elevated in patients with coronary bare metal stent restenosis. Acta Cardiol. 2018, 73, 69-74. [CrossRef] [PubMed]

16. Maniatis, K.; Siasos, G.; Oikonomou, E.; Vavuranakis, M.; Zaromytidou, M.; Mourouzis, K.; Paraskevopoulos, T.; Charalambous, G.; Papavassiliou, A.G.; Tousoulis, D. Osteoprotegerin and Osteopontin Serum Levels are Associated with Vascular Function and Inflammation in Coronary Artery Disease Patients. Curr. Vasc. Pharmacol. 2020, 18, 523-530. [CrossRef] [PubMed]

17. Lorenzen, J.M.; Schauerte, C.; Hübner, A.; Kölling, M.; Martino, F.; Scherf, K.; Batkai, S.; Zimmer, K.; Foinquinos, A.; Kaucsar, T.; et al. Osteopontin is indispensible for AP1-mediated angiotensin II-related miR-21 transcription during cardiac fibrosis. Eur. Heart J. 2015, 36, 2184-2196. [CrossRef] [PubMed]

18. Lorenzen, J.M.; Neunhöffer, H.; David, S.; Kielstein, J.T.; Haller, H.; Fliser, D. Angiotensin II receptor blocker and statins lower elevated levels of osteopontin in essential hypertension-Results from the EUTOPIA trial. Atherosclerosis 2010, 209, 184-188. [CrossRef]

19. Lind, L.; Gigante, B.; Borné, Y.; Feldreich, T.; Leppert, J.; Hedberg, P.; Östgren, C.J.; Nyström, F.H.; Sundström, J.; Ärnlöv, J.; et al. Plasma Protein Profile of Carotid Artery Atherosclerosis and Atherosclerotic Outcomes: Meta-Analyses and Mendelian Randomization Analyses. Arterioscler. Thromb. Vasc. Biol. 2021, 41, 1777-1788. [CrossRef]

20. Lind, L.; Ärnlöv, J.; Lindahl, B.; Siegbahn, A.; Sundström, J.; Ingelsson, E. Use of a proximity extension assay proteomics chip to discover new biomarkers for human atherosclerosis. Atherosclerosis 2015, 242, 205-210. [CrossRef]

21. Lind, L.; Gigante, B.; Borne, Y.; Mälarstig, A.; Sundström, J.; Ärnlöv, J.; Ingelsson, E.; Baldassarre, D.; Tremoli, E.; Veglia, F.; et al. The plasma protein profile and cardiovascular risk differ between intima-media thickness of the common carotid artery and the bulb: A meta-analysis and a longitudinal evaluation. Atherosclerosis 2020, 295, 25-30. [CrossRef] [PubMed] 